\title{
O Brasil pode repetir o milagre econômico?
}

\author{
FERNANDO DE HOLANDA BARBOSA \\ FERNANDO DE HOLANDA BARBOSA FILHO*
}

Can Brazil repeat the economic miracle? This article analyze the necessary conditions for Brazilian income per capita to duplicate in a time span of fifteen years, as it happened in the 1970s. Growth accounting is used to identify the sources of growth of Asian countries (China, Hon Kong, Japan, Singapore, South Korea and Taiwan) and Brazil during periods where income per capita has doubled in the past. The main restriction for the Brazilian economy to get back the growth performance of the 1970s is the low rate of investment. To increase this rate requires a substantial increase of the domestic savings rate.

Keywords: duplicating income per capita; growth accounting; Brazilian "miracle"; Asian model.

JEL Classification: O40, O47.

\section{INTRODUÇÃO}

Este artigo tem como objetivo analisar as condições macroeconômicas necessárias para que o Brasil dobre a renda per capita em quinze anos no futuro próximo. Esta meta de crescimento médio do produto no intervalo de 5,2\% a 5,7\% implica o crescimento do produto per capita de $4,5 \%$ a $5 \%$ ao ano. Ela não é trivial como nos ensina a história brasileira e a experiência internacional.

A Tabela 1 mostra que o Brasil foi capaz de duplicar a renda per capita em

\footnotetext{
* Respectivamente, professor da Escola de Pós-Graduação em Economia da Fundação Getulio Vargas (EPGE/FGV), e-mail: fernando.holanda@fgv.br; Pesquisador do Centro de Crescimento Econômico do Instituto Brasileiro de Economia da FGV (IBRE/FGV) e professor da Fundação Getúlio Vargas, e-mail: fernando.filho@fgv.br. O autor agradece ao Instituto Nacional de Ciência e Tecnologia do Conselho Nacional de Desenvolvimento Científico e Tecnológico (INCT/CNPq) e à Fundação de Amparo à Pesquisa do Estado do Rio de Janeiro (FAPERJ) pelo auxílio financeiro. Os autores agradecem Paulo Henrique Peruchetti pela assistência na pesquisa.
} 
quinze anos no período militar, na época do milagre econômico ${ }^{1}$. Os demais países da América Latina não foram capazes de duplicar a renda per capita em quinze anos nos últimos sessenta anos.

China, Coreia do Sul, Hong Kong, Japão, Cingapura e Taiwan dobraram a renda per capita, em quinze anos ou menos, em diferentes períodos, como assinala a Tabela 1, mostrando o sucesso do modelo asiático de crescimento econômico. O Japão foi o precursor deste modelo que foi copiado e adaptado às circunstâncias locais pelos demais países asiáticos. A experiência exitosa destes países deve ser analisada para nos ajudar a formular uma estratégia que nos permita sair da armadilha de baixo crescimento econômico das últimas três décadas. A segunda seção deste trabalho analisa a experiência asiática com o objetivo de identificar as fontes do sucesso deste modelo.

Tabela 1: Duplicação da Renda Per Capita em 15 anos.

\begin{tabular}{|c|c|}
\hline Países & Período \\
\hline Brasil & $1971-1982$ \\
\hline China & $1984-2011$ \\
\hline Coreia do Sul & $1973-2007$ \\
\hline Hong Kong & $1972-1995$ \\
\hline Japão & $1961-1984$ \\
\hline Cingapura & $1971-1997$ \\
\hline Taiwan & $1966-2003$ \\
\hline
\end{tabular}

O Brasil já teve sua época de tigre asiático durante o regime militar. Quais foram as fontes deste crescimento rápido? Será possível repetir o milagre econômico num ambiente democrático? A terceira seção deste trabalho procura responder a essas perguntas. A quarta seção analisa as perspectivas de crescimento econômico brasileiro mostrando as condições necessárias para a duplicação do produto per capita num período de quinze anos.

Num livro recente, Acemoglu e Robinson (2012) divulgaram para o grande público uma hipótese que tinham desenvolvido em artigos publicados em revistas especializadas em anos anteriores. A hipótese atribui o sucesso do crescimento econômico a construção de instituições não excludentes que permitam a participação de todos os grupos da sociedade nesse processo. A quinta seção deste trabalho procura traçar um roteiro das mudanças institucionais que deveriam ser levadas a cabo para que se acabe com o dualismo da sociedade brasileira, caracterizado pela coexistência de instituições excludentes e não excludentes. Essa seção apresenta também recomendações de política econômica para aumentar a

\footnotetext{
${ }^{1}$ O país continuou dobrando o PIB em período de quinze anos até 1982 devido ao forte crescimento de meados da década de 1970, que sustentou crescimento médio acima dos 5,2\% ao ano até 1982 .
} 
taxa de crescimento do produto per capita que permita atingir a meta de duplica-lo num período de quinze anos. A sexta seção traz um resumo das principais conclusões do trabalho.

\section{A EXPERIÊNCIA ASIÁTICA}

Seis países asiáticos, China, Coreia do Sul, Hong Kong, Japão, Cingapura e Taiwan, conseguiram durante longo período de tempo duplicar o PIB per capita a cada quinze anos, ou em períodos mais curtos, com taxas médias de crescimento iguais ou superiores a $4,7 \%$ ao $a^{2} o^{2}$. O intervalo de tempo que esses países dobraram a renda per capita não foi o mesmo, o menor intervalo foi do Japão com 21 anos e o maior aconteceu em Taiwan com 38 anos. A última experiência, ainda em curso, é a chinesa que já dura mais de 28 anos.

A Figura 1 mostra gráficos dos seis países asiáticos comparando-os com o tempo que o Brasil levou para duplicar o padrão de vida de sua população. Os dados mostram que os países asiáticos conseguiram manter por um intervalo de tempo maior do que o Brasil uma taxa de crescimento do PIB per capita que permitia a renda per capita dobrar em no máximo quinze anos.

Figura 1: Tempo Necessário para Dobrar o PIB Per Capita por País
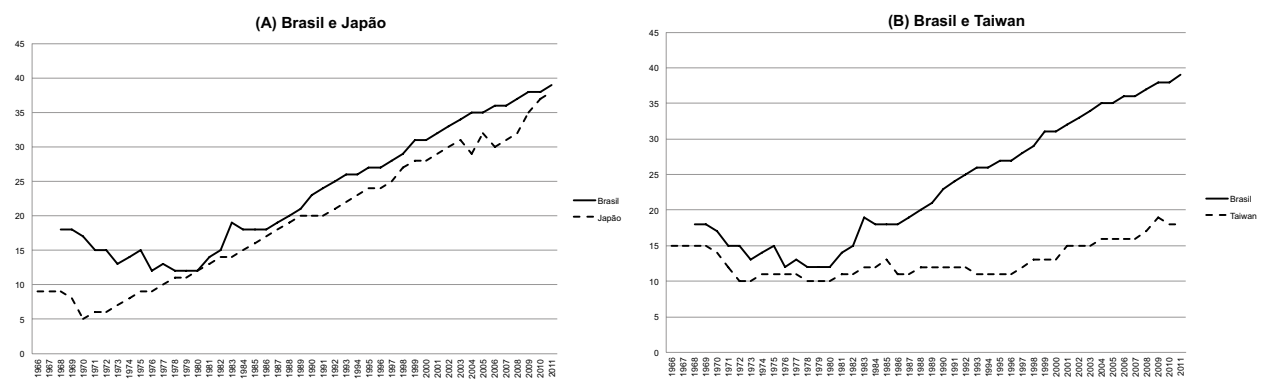

(C) Brasil e Hong Kong

(D) Brasil e Cingapura
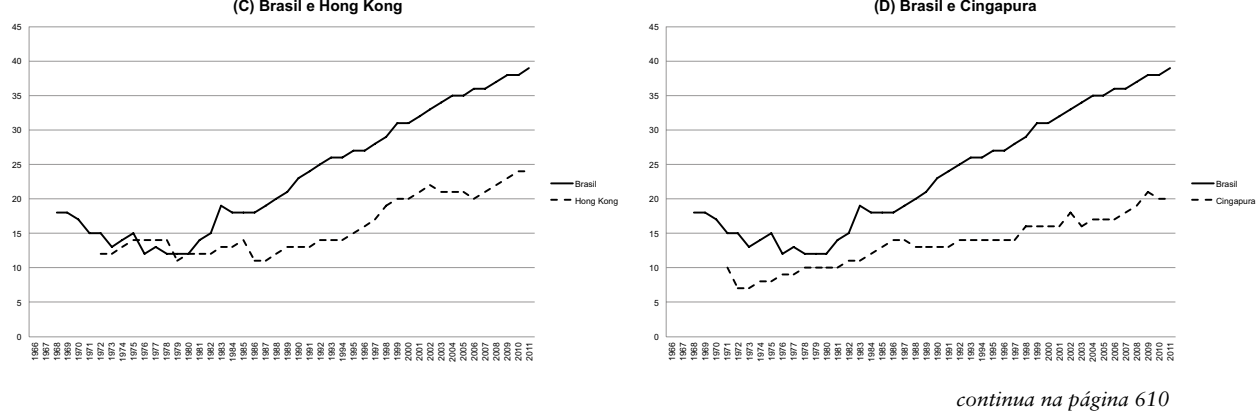

${ }^{2}$ Os dados utilizados na análise foram obtidos da Penn World Table 8.0. 

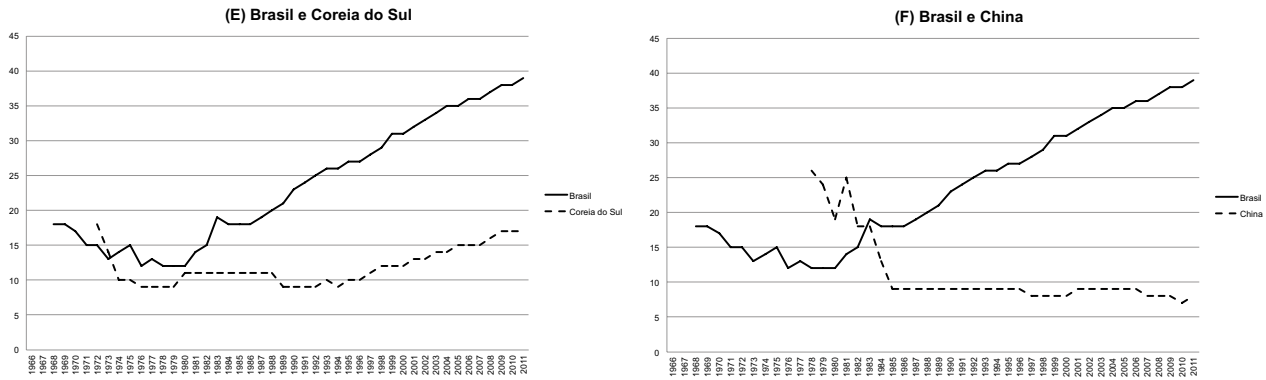

O Japão foi o primeiro dos países asiáticos a dobrar o PIB per capita em no máximo quinze anos. O Japão conseguiu este feito entre 1960 e 1981 e teve uma elevação substancial da renda per capita de forma a tornar-se um país "rico" Depois deste período, o PIB japonês tem necessitado de períodos de tempo cada vez maiores para dobrar o padrão de vida de sua população.

O segundo país a iniciar trajetória similar foi Taiwan, apresentada no quadro (B) da Figura 1. A partir de 1965, o país começa a dobrar o PIB em períodos inferiores a quinze anos. Assim como ocorreu com o Japão, Taiwan segue essa dinâmica de elevado crescimento por longo período de tempo, superando o Japão e conseguindo dobrar o PIB per capita em menos de quinze anos ao longo de 38 anos. Nesse processo, Taiwan deixa de ser uma economia pobre (15\% do PIB americano) e passa a ser uma economia com PIB per capita elevado (61\% em 2003) e continua crescendo em ritmo forte (dobrando o PIB em menos de vinte anos) até 2010 quando sua renda per capita atingiu $79 \%$ da americana.

Hong Kong, em 1970, também começa a dobrar o PIB per capita em intervalo inferior a quinze anos e continuou a fazê-lo por 24 anos até 1994. A partir de 1994, a taxa de crescimento cai gradativamente com o país dobrando o PIB em mais de vinte anos somente a partir de 2001. Neste período, o PIB per capita de Hong Kong relativo aos Estados Unidos aumenta de 39\% em 1970 para 105\% em 2010, uma renda per capita 5\% superior à americana.

Cingapura atinge o crescimento necessário para dobrar o PIB em menos de quinze anos em 1972 com um PIB relativo ao americano de 34\% e mantém esse elevado ritmo de crescimento por 25 anos até 1997 quando sua renda per capita atinge $84 \%$ da renda americana. A partir de 1997 , o crescimento da renda per capita mantém um ritmo elevado, ainda que inferior aos 25 anos anteriores, dobrando o padrão de vida num intervalo de dezoito anos em 2010. Dessa forma, Cingapura atinge uma renda per capita $1 \%$ superior à americana em 2010, apresentando uma taxa de crescimento ainda elevada.

A Coreia do Sul inicia em 1973 seu período de crescimento no qual dobra a renda per capita em tempo inferior a quinze anos. O país que possuía renda rela-

\footnotetext{
${ }^{3}$ Em 1980 (2010) a renda per capita japonesa equivalia a 73\% (76\%) da renda per capita americana, enquanto em 1960 o PIB per capita japonês representava somente $29 \%$ da renda americana.
} 
tiva à americana de $15 \%$ inicia sua trajetória de crescimento rápido e atinge renda per capita de 57\% da americana em 2004 quando seu PIB para de dobrar em menos de quinze anos. No entanto, as condições de vida continuam a melhorar de forma rápida com o país atingindo $69 \%$ da renda per capita dos Estados Unidos em 2010 enquanto dobrava o seu PIB em dezoito anos, apresentando um crescimento ainda elevado.

A China foi o último dos países asiáticos a dobrar o produto per capita em período inferior a quinze anos em 1984. Desde então a China tem apresentado taxas de crescimento extremamente elevadas com o país sendo capaz de aumentar em $100 \%$ o PIB per capita em períodos de somente oito anos. Esse elevado crescimento da renda per capita fez com que o PIB per capita relativo se ampliasse de $3 \%$ da renda per capita americana em 1984 para $21 \%$ em 2010. A China continua com taxas de crescimento extremamente elevadas o que indica que sua renda per capita deve continuar em elevado ritmo de expansão pelos próximos anos.

\section{Decomposição do crescimento}

Quais as variáveis que ajudam a explicar como os países asiáticos conseguiram manter o crescimento elevado por tanto tempo e passar de país "pobre" ou de renda média para país "rico" 4

O crescimento do produto per capita tem quatro componentes: i) acumulação do capital físico, com aumento da intensidade do capital por trabalhador, ii) acumulação de capital humano, iii) expansão da produtividade total dos fatores (PTF) e iv) evolução da participação da força de trabalho com aumento da relação trabalhador/população. A decomposição do produto per capita é realizada conforme a expressão:

$$
y=\frac{Y}{P o p}=A\left(\frac{K}{L}\right)^{\alpha} \frac{L}{P o p}=A_{H}\left(\frac{K}{L}\right)^{\alpha} H^{1-\alpha} \frac{L}{P o p}=A_{H} k^{\alpha} H^{1-\alpha} l
$$

O produto per capita é função da produtividade $(A)$, do capital por trabalhador $(K / L)$, do capital humano $(H)$ e da razão entre trabalhadores e população $(L / P o p)$. Por sua vez a produtividade $(A)$ depende do capital humano $(H)$ e da produtividade mensurada não se levando em conta o capital humano $\left(A_{H}\right)^{5}$. Logo, com base na equação (1) pode-se decompor o crescimento anual do produto per capita de acordo com:

$$
\hat{y}=\hat{A}_{H}+\alpha \times \hat{k}+(1-\alpha) \hat{H}+\hat{l}
$$

\footnotetext{
${ }^{4}$ Somente a China ainda não fez essa transição. Mas o elevado crescimento dos próximos anos deve fazer com que a mesma atinja níveis de renda per capita mais elevados do que o do Brasil em breve.

${ }^{5}$ O capital humano é calculado com base nos dados de Barro e Lee (2010) e com o formato funcional de Bils e Klenow (2000) conforme $H=\exp \left(\frac{\theta}{1-\psi} h^{1-\psi}\right)$.
} 
A notação é a seguinte: $\hat{y}$ é a variação anual do produto por trabalhador, $\hat{A}_{H}$ a variação da produtividade total dos fatores não levando-se em conta o capital humano, $\hat{k}$ a variação do capital por trabalhador, $\hat{H}$ a variação do capital humano e $\hat{l}$ a variação da razão entre trabalhadores e a população.

\section{Japão}

O Japão dobrou o PIB a cada quinze anos entre 1960 e 1981. A Tabela 2 contém a decomposição do crescimento do produto per capita. Nesse período, a decomposição mostra que de 1950 a 1960 a maior parte deste crescimento foi fruto de ganhos da produtividade total dos fatores, fenômeno que se ampliou ao longo da década de 1960. A partir da década de 1970, o aumento do capital por trabalhador ganha importância e permite um crescimento elevado a despeito da evolução negativa da PTF. A década de 1980 mostra recuperação da PTF com a mesma tendo peso similar ao do capital físico na explicação do crescimento da renda per capita.

A partir da década de 1990, a economia japonesa fica estagnada com aumento do capital por trabalhador contrabalançado por perda da produtividade nos anos noventa e diminuição da taxa de crescimento da relação capital/trabalho e estagnação da PTF entre 2000 e 2010.

Tabela 2: Decomposição do Crescimento do Produto Per Capita no Japão

\begin{tabular}{lccc|ccc}
\hline & \multicolumn{2}{c|}{ PIB por Trabalhador } & \multicolumn{3}{c}{ PIB per capita } \\
& PTFH & K/L & H & Y/L & L/POP & Total \\
\hline $1950-1960$ & 2,7 & 2,0 & 0,7 & 5,3 & 1,0 & 6,4 \\
$1960-1970$ & 6,7 & 3,9 & 0,1 & 10,7 & 0,3 & 11,0 \\
$1970-1980$ & $-0,2$ & 3,2 & 0,6 & 3,5 & $-0,3$ & 3,3 \\
$1980-1990$ & 1,4 & 1,9 & 0,4 & 3,6 & 0,4 & 4,0 \\
$1990-2000$ & $-0,9$ & 1,3 & 0,5 & 0,9 & $-0,1$ & 0,8 \\
$2000-2010$ & 0,3 & 0,6 & 0,3 & 1,2 & $-0,5$ & 0,7 \\
\hline $1961-1984$ & 2,7 & 3,2 & 0,4 & 6,2 & 0,0 & 6,3 \\
\hline $1956-1984$ & 2,8 & 3,2 & 0,4 & 6,3 & 0,1 & 6,5 \\
\hline
\end{tabular}

A Tabela 2 mostra, ainda, que o capital humano contribui de forma positiva durante todo o período de análise com o pico atingindo $0,6 \%$ ao ano na década de 1970 e o mesmo explicando um crescimento da renda per capita de $0,3 \%$ ao ano na primeira década do século XXI.

Outro aspecto importante da Tabela 2 é a baixa importância da elevação da proporção de trabalhadores na população (L/POP) para o crescimento japonês mesmo no período de pico, entre 1960 e 1970.

Por último, percebe-se que no período em que a economia japonesa dobrou o 
PIB per capita a cada quinze anos, capital físico e humano contribuíram com cerca de $60 \%$ do crescimento de $6,3 \%$ ao ano.

\section{Taiwan}

A análise do crescimento do produto por trabalhador de Taiwan entre $1960 \mathrm{e}$ 2010 mostra que o crescimento da PTF foi importante entre 1961 e 2003, com a produtividade crescendo em ritmo de $1,8 \%$ ao ano durante quase quatro décadas. No entanto mais surpreendente no caso de Taiwan é a elevada contribuição do capital físico (3,8\% a.a.) e do capital humano (1,0\% a.a.) no mesmo período. A partir de 1990 a PTF passa a crescer em ritmo mais baixo com uma expansão inferior a $1 \%$ ao ano. No entanto, a forte expansão dos fatores de produção mantém um crescimento do PIB per capita de $6 \%$ ao ano. A partir do século XXI, a taxa de crescimento do PIB per capita se reduz para $3,4 \%$ ao ano, com o capital contribuindo com $1,2 \%$ desse crescimento. A Tabela 3 mostra ainda a importante contribuição da elevação da parcela de trabalhadores na população ocorrida nas década de 1970 e 1980 para o crescimento do PIB.

Tabela 3: Decomposição do Crescimento do Produto Percapita em Taiwan

\begin{tabular}{lccc|ccc}
\hline & \multicolumn{3}{c|}{ PIB por Trabalhador } & \multicolumn{3}{c}{ PIB per capita } \\
& PTFH & K/L & H & Y/L & L/POP & Total \\
\hline $1960-1970$ & 2,7 & 2,5 & 0,8 & 6,0 & $-0,2$ & 5,8 \\
$1970-1980$ & 0,8 & 3,6 & 0,9 & 5,4 & 1,9 & 7,3 \\
$1980-1990$ & 1,6 & 2,7 & 0,6 & 4,9 & 1,1 & 6,0 \\
$1990-2000$ & 0,9 & 3,1 & 0,7 & 4,7 & 0,5 & 5,1 \\
$2000-2010$ & 1,0 & 1,2 & 0,6 & 2,8 & 0,6 & 3,4 \\
\hline $1966-2003$ & 1,2 & 4,0 & 1,1 & 6,3 & 1,6 & 7,9 \\
\hline $1961-2003$ & 1,8 & 3,8 & 1,0 & 6,7 & 1,0 & 7,7 \\
\hline
\end{tabular}

No período de 1966 a 2003, em que o PIB per capita cresceu em ritmo mais elevado, a contribuição do crescimento dos fatores de produção (capital físico, humano e trabalho) explica $85 \%$ do crescimento $(6,7 \% / 7,9 \%)$ de Taiwan.

\section{Hong Kong}

Hong Kong inicia o período de forte crescimento com o aumento da força de trabalho na população que explica integralmente o crescimento do PIB per capita entre 1960 e 1970. Na década de 1970, observa-se aceleração da PTF (2,2\%) acompanhada de ampliação do capital por trabalhador (1,5\%), capital humano $(1,0 \%)$ e do aumento da participação do trabalho na população $(1,5 \%)$. Na década de 1980, o desempenho da produtividade se mantém elevado assim como a expansão dos fatores de produção, com o capital físico contribuindo com 1,8\% ao ano para o crescimento. É interessante observar a grande importância do investi- 
mento em capital humano que contribui entre 1960 e 1990 em quase $1 \%$ ao ano para a elevação do PIB per capita.

Tabela 4: Decomposição do Crescimento do Produto Per Capita em Hong Kong

\begin{tabular}{lccc|ccc}
\hline & \multicolumn{3}{c|}{ PIB por Trabalhador } & \multicolumn{3}{c}{ PIB per capita } \\
& PTFH & K/L & H & Y/L & L/POP & Total \\
\hline $1960-1970$ & $-1,1$ & $-0,5$ & 1,0 & $-0,6$ & 6,2 & 5,6 \\
$1970-1980$ & 2,2 & 1,5 & 1,0 & 4,7 & 1,5 & 6,2 \\
$1980-1990$ & 1,8 & 1,8 & 0,8 & 4,4 & 0,7 & 5,1 \\
$1990-2000$ & 0,3 & 1,9 & $-0,1$ & 2,2 & 0,1 & 2,3 \\
$2000-2010$ & 1,7 & 1,2 & 0,6 & 3,4 & 0,2 & 3,6 \\
\hline $1972-1995$ & 1,9 & 1,8 & 0,7 & 4,4 & 0,8 & 5,2 \\
\hline $1967-1995$ & 1,8 & 1,4 & 0,7 & 4,0 & 1,4 & 5,3 \\
\hline
\end{tabular}

Nos anos 1990 observa-se um aumento do capital por trabalhador acompanhado por estagnação do capital humano (-0,1\% a.a.) e da PTF (0,3\% a.a.). A partir de 2000 o crescimento do PIB per capita se recupera devido ao crescimento da PTF que explica quase $50 \%$ do crescimento.

A acumulação de fatores de produção explica mais de $60 \%$ da expansão da renda per capita de Hong Kong no período compreendido entre 1972 e 1995, época em que o país duplica a renda per capita em quinze anos ou menos.

\section{Cingapura}

A Tabela 5 mostra a decomposição do crescimento do produto per capita de Cingapura. Os dados mostram que entre 1960 e 1970 a maior parte do crescimento decorre de elevações substancias da PTF explicando quase $50 \%$ do crescimento. Nesse período inicial, o crescimento do capital por trabalhador foi de $1,3 \%$ acompanhado da ampliação do capital humano que contribuiu com um crescimento de $1,2 \%$ ao ano. O crescimento ganha força na década de 1970 quando há maior contribuição do capital por trabalhador para o crescimento do produto $(2,5 \%$ a.a. $)$ e aumento substancial do fator trabalho (a razão L/POP cresce 3,2\% a.a.). O crescimento da produtividade total dos fatores é razoável contribuindo com 1,4\% a.a. no período.

Tabela 5: Decomposição do Crescimento do Produto Per Capita em Cingapura

\begin{tabular}{cccc|ccc}
\hline & \multicolumn{3}{c|}{ PIB por Trabalhador } & \multicolumn{3}{c}{ PIB per capita } \\
& PTFH & K/L & H & Y/L & L/POP & Total \\
\hline $1960-1970$ & 3,3 & 1,3 & 1,2 & 5,8 & 0,6 & 6,4 \\
$1970-1980$ & 1,4 & 2,5 & 0,0 & 3,9 & 3,2 & 7,1 \\
$1980-1990$ & 1,1 & 2,0 & 1,0 & 4,0 & 1,2 & 5,2 \\
$1990-2000$ & 1,2 & 2,0 & 0,9 & 4,1 & 0,2 & 4,3 \\
\hline
\end{tabular}




\begin{tabular}{llll|lll} 
continuação \\
\hline $2000-2010$ & 0,5 & 0,4 & 0,6 & 1,5 & 1,4 & 2,9 \\
\hline $1971-1997$ & 1,2 & 2,0 & 0,6 & 3,9 & 1,9 & 5,8 \\
\hline $1966-1997$ & 1,9 & 2,2 & 0,7 & 4,8 & 1,8 & 6,6 \\
\hline
\end{tabular}

A década de 1980 registra uma redução da taxa de crescimento do produto devido à desaceleração do aumento da participação do trabalho e leve desaceleração da produtividade. Nesse período a relação capital/trabalho explica a maior parte do crescimento contribuindo com $2,0 \%$ a.a. enquanto o capital humano contribui com $1 \%$ a.a.

A década de 1990 mostra a manutenção do crescimento da produtividade ( $1,2 \%$ a.a.) que contribui para o crescimento em importância parecida com a elevação do capital humano (0,9\% a.a.). O investimento em capital físico que ampliou o capital por trabalhador foi o fator mais importante no período para o crescimento do produto per capita de 4,3\% ao ano. Entre 2000 e 2010, o PIB por trabalhador cresceu $1,5 \%$ a.a. com redução da contribuição do capital por trabalhador e da produtividade. A queda do crescimento do produto por trabalhador (Y/L) faz com que o tempo para duplicar o PIB per capita aumente de forma gradativa, significando, o fim do ciclo de grande crescimento.

Durante o período 1971-1997 no qual Cingapura foi capaz de ampliar em mais de $100 \%$ o produto per capita em menos de quinze anos, a produtividade explicou no máximo pouco mais de $20 \%$ desse crescimento. A maior parte do crescimento do produto per capita foi fruto da ampliação dos fatores de produção.

\section{Coreia do Sul}

A partir de 1973 o período para dobrar o PIB per capita na Coreia do Sul é inferior a quinze anos. Esse ritmo de crescimento é mantido até 2007. Durante esse período, mais de $75 \%$ do crescimento de renda per capita, superior a $6 \%$ ao ano, foi fruto da acumulação dos fatores de produção.

Entre 1960 e 1970 o forte crescimento do PIB prepara o ambiente para a aceleração do crescimento da década seguinte. $\mathrm{O}$ crescimento do produto per capita na década de 1960 é fruto do crescimento simultâneo do capital por trabalhador $(1,8 \%$ a.a.) e do capital humano (1,5\% a.a.).

A aceleração do crescimento na década de 1970 , com o PIB per capita crescendo $6,8 \%$ ao ano, decorre do investimento em capital físico (2,8\% a.a.), do aumento da participação do trabalho na população $(1,9 \%$ a.a.) e do investimento em capital humano (1,2\% a.a.).

A Coreia do Sul apresenta crescimento ainda mais forte na década de 1980 quando o crescimento da produtividade ganha destaque com a mesma contribuindo com $2,8 \%$ ao ano, pouco menos do que da relação capital/trabalho que possibilita um crescimento de $2,9 \%$ ao ano. O capital humano contribui com $0,6 \%$ ao ano na década e a elevação da razão trabalhadores/população ( $L / P O P)$ com 1,6\% ao ano. 
Tabela 6: Decomposição do Crescimento do Produto Per Capita na Coreia do Sul

\begin{tabular}{lccc|ccc}
\hline & \multicolumn{3}{c|}{ PIB por Trabalhador } & \multicolumn{3}{c}{ PIB per capita } \\
& PTFH & K/L & H & Y/L & L/POP & Total \\
\hline $1960-1970$ & 0,8 & 1,8 & 1,5 & 4,0 & 0,8 & 4,8 \\
$1970-1980$ & 1,0 & 2,8 & 1,2 & 5,0 & 1,9 & 6,8 \\
$1980-1990$ & 2,8 & 2,9 & 0,6 & 6,3 & 1,6 & 7,9 \\
$1990-2000$ & 0,7 & 3,4 & 0,9 & 5,0 & 0,7 & 5,6 \\
$2000-2010$ & 0,7 & 1,7 & 0,4 & 2,8 & 0,8 & 3,6 \\
\hline $1973-2007$ & 1,3 & 2,9 & 0,7 & 4,9 & 1,2 & 6,1 \\
\hline $1968-2007$ & 1,5 & 2,8 & 0,8 & 5,1 & 1,3 & 6,4 \\
\hline
\end{tabular}

A década de 1990 mostra o início da desaceleração do crescimento no país com grande redução da taxa de crescimento da produtividade $(2,1 \%$ ao ano inferior a década anterior) apesar do forte crescimento do capital por trabalhador. $\mathrm{Na}$ década seguinte ocorre redução ainda mais forte do crescimento do produto per capita devido ao decréscimo da taxa de crescimento do capital por trabalhador não compensada por uma recuperação da produtividade.

\section{China}

A China é o último dos países asiáticos que duplica a renda per capita em período inferior a quinze anos. A Tabela 7 mostra que o crescimento do produto por trabalhador aumenta na década de 1970 , quando atinge $2,7 \%$ ao ano com expansão do produto per capita de 4,2\% a.a. A partir de 1984, a China passa a dobrar o PIB per capita devido ao forte crescimento da produtividade que, a partir da década de 1980 , cresce a taxas médias superiores a $4 \%$ ao ano. Este ciclo mostra grande expansão da produtividade acompanhada por aumento da relação capital/trabalho $(3,3 \%$ a.a.) com a produtividade sendo a principal fonte de crescimento.

O crescimento do capital humano que era superior a $1 \%$ ao ano entre 1960 e 1979 diminui nas décadas seguintes. Todavia, contribui na pior das hipóteses para um crescimento do PIB per capita de $0,6 \%$ ao ano.

Tabela 7: Decomposição do Crescimento do Produto Per Capita na China

\begin{tabular}{lccc|ccc}
\hline & \multicolumn{2}{c|}{ PIB por Trabalhador } & \multicolumn{3}{c}{ PIB per capita } \\
& PTFH & K/L & H & Y/L & L/POP & Total \\
\hline $1960-1970$ & $-1,2$ & 0,6 & 1,2 & 0,5 & 0,4 & 0,9 \\
$1970-1980$ & 0,0 & 1,6 & 1,1 & 2,7 & 1,4 & 4,2 \\
$1980-1990$ & 3,8 & 1,6 & 0,6 & 6,0 & 1,3 & 7,3 \\
$1990-2000$ & 4,4 & 3,3 & 1,0 & 8,7 & 0,2 & 8,9 \\
$2000-2010$ & 4,4 & 4,1 & 0,6 & 9,1 & 0,3 & 9,4 \\
\hline $1984-2011$ & 4,2 & 3,3 & 0,7 & 8,2 & 0,4 & 8,6 \\
\hline $1979-2011$ & 4,1 & 3,0 & 0,7 & 7,8 & 0,6 & 8,5 \\
\hline
\end{tabular}


A partir da década de 1990 a taxa de crescimento do PIB por trabalhador ganha força com o maior crescimento do capital por trabalhador que passa a contribuir com um crescimento adicional superior a 3\% ao ano. Com isso, a China atinge um crescimento do produto per capita que dobra o PIB per capita em intervalos de tempo inferiores de oito anos.

\section{O milagre asiático}

O milagre é um evento não explicado pela ciência e atribuído à origem divina. A técnica da contabilidade do crescimento econômico aplicada aos seis países asiáticos, China, Coreia do Sul, Hong Kong, Japão, Cingapura e Japão nos leva a concluir que, com exceção da $\mathrm{China}^{6}$, o sucesso desses países não se deve a ocorrência de milagres, mas sim a acumulação de capital físico e de capital humano. Nos períodos de duplicação do PIB per capita em menos de quinze anos, somente o Japão consegue crescimentos elevados da produtividade embora inferiores ao crescimento do capital por trabalhador. Nos demais países durante o período em que o PIB per capita dobra em menos de quinze anos a produtividade cresce menos de $2 \%$ ao ano.

Tabela 8: Poupança por País

\begin{tabular}{ccccccccc}
\hline & Brasil & França & EUA & China & Coreia do Sul & Cingapura & Japão & Hong Kong \\
\hline 1980 & 17,96 & 22,85 & 19,47 & 32,59 & 25,01 & 31,89 & 30,73 & 33,42 \\
1990 & 19,35 & 20,89 & 15,82 & 39,22 & 37,58 & 43,03 & 33,62 & 35,13 \\
2000 & 14,49 & 21,35 & 18,09 & 36,83 & 33,34 & 43,99 & 27,63 & 31,67 \\
2009 & 18,03 & 17,71 & 12,21 & 52,23 & 32,42 & 48,42 & 23,54 & 29,40 \\
\hline
\end{tabular}

A acumulação de capital físico resultou de uma elevada taxa de investimento financiado por poupança doméstica. A Tabela 8 mostra que nos períodos de duplicação da renda per capita em quinze anos ou menos as taxas de poupança desses países eram superiores a $30 \%$ do PIB.

Tabela 9: Escolaridade Média por País

\begin{tabular}{cccccccccc}
\hline & Brasil & França & EUA & China & Coreia do Sul & Cingapura & Japão & Hong Kong & Taiwan \\
\hline $1970-1979$ & 2,68 & 5,49 & 11,38 & 3,95 & 7,19 & 5,12 & 8,68 & 6,93 & 6,75 \\
$1980-1989$ & 3,56 & 6,65 & 12,10 & 5,17 & 8,93 & 5,88 & 9,64 & 8,60 & 8,11 \\
$1990-1999$ & 5,28 & 8,43 & 12,53 & 6,30 & 10,29 & 7,28 & 10,45 & 9,34 & 9,30 \\
$2000-2009$ & 7,01 & 9,91 & 12,89 & 7,57 & 11,42 & 8,48 & 11,22 & 9,78 & 10,75 \\
\hline
\end{tabular}

A acumulação de capital humano supõe a existência de um sistema educacional que além de universal seja capaz de reter os alunos na escola e preparar os mesmos para o mercado de trabalho. A Tabela 9 mostra a escolaridade média em

\footnotetext{
${ }^{6}$ Os elevados ganhos de produtividade da China devem estar associados aos ganhos na alocação de recursos da transformação de uma economia planejada numa economia de mercado e a mudança de composição reduzindo a participação da mão de obra no campo.
} 
cinco países asiáticos, na França, nos Estados Unidos e no Brasil. Os dados estão agrupados por décadas, começando na década de 70 e terminando na década de 2000. Os países asiáticos aumentaram nestas quatro décadas a escolaridade média de suas populações. Japão, Coreia do Sul e Taiwan já ultrapassaram a França e estão quase no nível americano. Cingapura e Hong Kong estão próximos do nível francês. O Brasil continua atrás da China, em termos de escolaridade média, a despeito da taxa de crescimento desta variável ter sido maior no Brasil nas quatro décadas analisadas na Tabela 9.

\section{A EXPERIÊNCIA BRASILEIRA}

O Brasil somente foi capaz de crescer o PIB per capita de forma a dobrá-lo em menos de quinze anos entre 1971 e 1982 . Como entender este fenômeno e o que aconteceu depois? Para fins de comparação internacional essa seção utiliza os dados da Penn World Table 8.0 para decompor o PIB per capita de forma a compará-lo com os países asiáticos. A Tabela 10 mostra a decomposição do PIB per capita do Brasil desde a década de 1950 até a primeira década do século XXI com a mesma metodologia usada para os países asiáticos.

Tabela 10: Decomposição do Crescimento do Produto Per Capita no Brasil

\begin{tabular}{lccc|ccc}
\hline & \multicolumn{2}{c|}{ PIB por Trabalhador (Y/L) } & \multicolumn{4}{c}{ PIB per capita } \\
& PTFH & K/L & H & Y/L & L/POP & Total \\
\hline $1950-1960$ & 3,0 & 0,3 & 0,8 & 4,0 & $-0,2$ & 3,8 \\
$1960-1970$ & 2,8 & 1,0 & 0,9 & 4,7 & $-0,4$ & 4,3 \\
$1970-1980$ & 2,6 & 2,1 & 0,0 & 4,6 & 1,3 & 5,9 \\
$1980-1990$ & $-3,6$ & 0,3 & 1,6 & $-1,7$ & 1,2 & $-0,5$ \\
$1990-2000$ & $-0,6$ & 0,7 & 1,4 & 1,5 & $-0,5$ & 1,0 \\
$2000-2010$ & 0,3 & 0,1 & 0,7 & 1,1 & 1,3 & 2,4 \\
\hline $1971-1980$ & 2,3 & 2,2 & 0,0 & 4,5 & 1,2 & 5,6 \\
\hline $1966-1980$ & 2,8 & 1,8 & 0,2 & 4,9 & 0,9 & 5,8 \\
\hline
\end{tabular}

O apogeu do crescimento do PIB per capita brasileiro deu-se na década de 1970 na qual o crescimento do PIB per capita atinge os 5,9\% a.a. Nesse período, a forte expansão da produtividade é o principal fator que explica o aumento do PIB per capita. O crescimento do capital físico por trabalhador e o aumento da participação da força de trabalho na população de $1,3 \%$ a.a. ano explicam o crescimento do PIB per capita de forma tão acelerada.

Diferentemente dos países asiáticos, chama a atenção o baixo investimento brasileiro em capital humano até a década de 1980 . Somente a partir dessa década que se inicia uma elevação da escolaridade média que produz expansão do capital humano. As décadas de 1960 e 1970 mostram a importância da produtividade no 
crescimento do Brasil quando as mesmas explicaram mais de $50 \%$ do crescimento do produto per capita. $\mathrm{Na}$ década de 1970 a produtividade acompanhada de aumento da relação capital/trabalho explicam $80 \%$ da forte expansão do PIB per capita.

A partir da década de 1980 a produtividade e o investimento em capital caem de forma substancial reduzindo a taxa de crescimento do produto no Brasil (por trabalhador e per capita). O aumento da taxa de desemprego na década de 1990 explica o crescimento do PIB per capita inferior ao do PIB por trabalhador. Esse movimento é revertido na década seguinte quando a redução da taxa de desemprego contribui para a elevação do PIB per capita de $2,4 \%$ ao ano, a maior taxa desde a década de 1970.

A análise do período no qual o Brasil duplica o PIB per capita em intervalo de no máximo quinze anos e cresce a taxas superiores a $5 \%$ ao ano mostra que a expansão da produtividade e do capital por trabalhadores são os fatores que mais explicam a rápida expansão do PIB per capita. No entanto, esse forte crescimento acaba na década de 1980 que apresenta forte desaceleração da produtividade e do investimento em capital físico, revertendo de forma rápida à taxa de crescimento do produto per capita brasileiro.

\section{O milagre brasileiro}

O milagre brasileiro diferente do asiático não teve contribuição do capital humano. As principais fontes do crescimento foram o aumento da produtividade total dos fatores, a acumulação de capital físico com o aumento da intensidade do capital por trabalhador e o aumento da participação da força de trabalho na população.

A contabilidade do crescimento não permite nenhuma conclusão sobre causalidade, sendo possível que o aumento da taxa de investimento produza aumento da produtividade total dos fatores, como também que o reverso ocorra, isto é, que o aumento da produtividade total dos fatores provoque aumento da taxa de investimento. Os dados dos países asiáticos, como também as informações da contabilidade do crescimento brasileiro, indicam que essas duas variáveis têm uma forte correlação positiva. Na década perdida, a década de 1980 no Brasil, a taxa de investimento despenca e a taxa de crescimento da produtividade total dos fatores é negativa.

\section{NOVO MILAGRE ECONÔMICO BRASILEIRO: CONDIÇÕES NECESSÁRIAS}

Quais as condições necessárias para um novo milagre econômico brasileiro? Para avaliar o crescimento do PIB nos próximos anos utilizamos os dados do IBGE: a série do PIB, a formação bruta de capital fixo e os respectivos deflatores implícitos tendo como referência os preços de 2012. Com base na série de formação bruta de capital fixo construiu-se a série de capital da economia. Os dados de trabalho foram 
obtidos do total de horas de trabalho de Barbosa Filho e Pessôa (2013). A fonte dos dados da utilização da capacidade instalada (NUCI) é a FGV e os de capital humano foram calculados com a metodologia de Bils e Klenow (2000) com dados de Barro e Lee (2010). A Tabela 11 mostra a decomposição do crescimento do PIB entre 2001 e 20127. A PTF calculada sem capital humano cresceu no Brasil a uma taxa de no máximo 2,3\% entre 2001 e 2012 . O capital físico contribuiu na melhor das hipóteses para o crescimento com 1,3\% ao ano, montante muito inferior ao observado nos períodos de maior crescimento econômico quando o crescimento do capital físico foi importante como mostra os dados da Tabela 10.

A Tabela 11 decompõe o crescimento do PIB incluindo capital humano e realiza análise similar para a última década ${ }^{8}$. Com capital humano, a expansão máxima da PTFH no período foi de $1,4 \%$. Esse crescimento da PTFH é muito inferior ao observado na Tabela 10 para as décadas de 1950,1960 e 1970.

Tabela 11: Decomposição do Crescimento do Produto entre 2001 e 2012

\begin{tabular}{ccccc}
\hline & PIB & PTF & Capital & Trabalho \\
\hline \multirow{2}{*}{$2001-2012$} & 3,4 & 1,3 & 1,2 & 1,0 \\
& & $(37,3)$ & $(33,9)$ & $(28,8)$ \\
$2001-2008$ & 3,9 & 1,6 & 1,1 & 1,2 \\
& & $(40,6)$ & $(28,1)$ & $(31,3)$ \\
$2003-2008$ & 4,7 & 2,3 & 1,3 & 1,1 \\
& & $(49,0)$ & $(26,6)$ & $(24,4)$ \\
$2008-2012$ & 2,6 & 0,8 & 1,3 & 0,6 \\
& & $(28,9)$ & $(48,8)$ & $(22,4)$ \\
$2010-2012$ & 1,8 & 0,0 & 1,4 & 0,4 \\
& & $(1,0)$ & $(77,9)$ & $(21,1)$ \\
\hline
\end{tabular}

Fonte: Barbosa Filho (2013).

A Tabela 11 mostra que os elementos mais importantes para a expansão do PIB entre 2001 e 2012 foram o capital físico e a razão trabalho/população que contribuíram, respectivamente, com $1,3 \%$ e $1,0 \%$ do crescimento anual de $3,4 \%$. No período de maior crescimento, a PTFH acelerou para $1,4 \%$ ao ano e a expansão dos fatores de produção $(K, H$ e $L)$ foi responsável pelos 3,3\% restantes.

Para fazer cenários de crescimento do PIB per capita de forma a possibilitar que o país volte a dobrar o PIB a cada quinze anos é necessário supor algumas hipóteses para as seguintes variáveis: taxa de crescimento populacional, participação do trabalho na população, capital humano e capital por trabalhador.

\footnotetext{
${ }^{7}$ A decomposição sem capital humano foi feita com base em $Y=A(u K)^{\alpha} L^{1-\alpha}$, em que $A$ é a PTF, $u$ é o NUCI, $K$ é o capital e $L$ o total de horas trabalhadas.

${ }^{8}$ A decomposição sem capital humano foi feita com base em $Y=A(u K)^{\alpha}(H L)^{1-\alpha}$, em que $A$ é a PTF, $u$ é o NUCI, $K$ é o capital, $\mathrm{H}$ capital humano e $L$ o total de horas trabalhadas.
} 
Tabela 12: Decomposição do Crescimento do Produto entre 2001 e 2012

\begin{tabular}{cccccc}
\hline & PIB & PTFH & Capital & Capital Humano & Trabalho \\
\hline \multirow{2}{*}{$2001-2012$} & 3,4 & 0,5 & 1,2 & 0,7 & 1,0 \\
& & $(15,7)$ & $(33,9)$ & $(21,6)$ & $(28,8)$ \\
$2001-2008$ & 3,9 & 0,6 & 1,1 & 1,0 & 1,2 \\
& & $(15,4)$ & $(28,1)$ & $(25,2)$ & $(31,3)$ \\
$2003-2008$ & 4,7 & 1,4 & 1,3 & 0,9 & 1,1 \\
& & $(30,7)$ & $(26,6)$ & $(18,3)$ & $(24,4)$ \\
$2008-2012$ & 2,6 & 0,4 & 1,3 & 0,3 & 0,6 \\
& & $(16,5)$ & $(48,8)$ & $(12,4)$ & $(22,4)$ \\
$2010-2012$ & 1,8 & $-0,2$ & 1,4 & 0,2 & 0,4 \\
& & $-(8,9)$ & $(77,9)$ & $(9,9)$ & $(21,1)$ \\
\hline
\end{tabular}

O crescimento do PIB per capita brasileiro não deve ter contribuição da razão trabalho/população nos próximos anos. O bônus demográfico, período no qual a população em idade ativa cresce em ritmo mais acelerado do que a população, está no fim e a queda da taxa de desemprego que determinou a importância da razão trabalho/população na última década não deve ocorrer de novo.

A Figura 2 mostra que o crescimento populacional brasileiro será inferior a um ponto percentual nos próximos anos com um crescimento médio de $0,64 \%$ ao ano entre 2013 e 2028. Isso implica que para o PIB per capita dobrar em intervalo de quinze anos o PIB total da economia deverá crescer a uma taxa próxima dos 5,4\% ao ano.

Para que o país tenha um crescimento substancial do capital por trabalhador, como ocorreu na década de 1970, a taxa de investimento terá que ser bem maior do que a taxa média de 16,3\% do PIB do período 2001-2012.

Figura 2: Taxa de Crescimento da População e da PIA

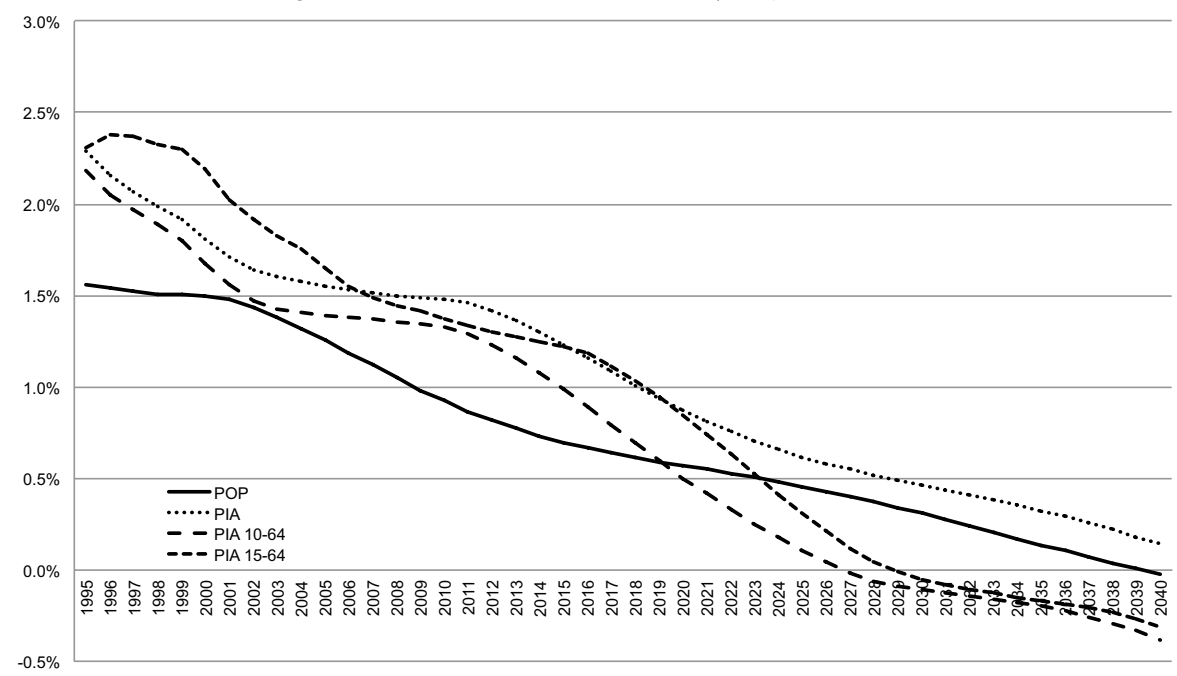


$\mathrm{Na}$ década de 1970 a taxa média de investimento foi de $24,9 \%$. Essa diferença de $8,6 \%$ da taxa de investimento representa uma redução de $3,3 \%$ no ritmo de crescimento do estoque de capital por trabalhador e redução de $1,4 \%$ na contribuição do capital para a taxa de crescimento do produto. Logo, o aumento da taxa de investimento é uma condição necessária para novo milagre econômico.

Figura 3: Taxa de Investimento no Brasil

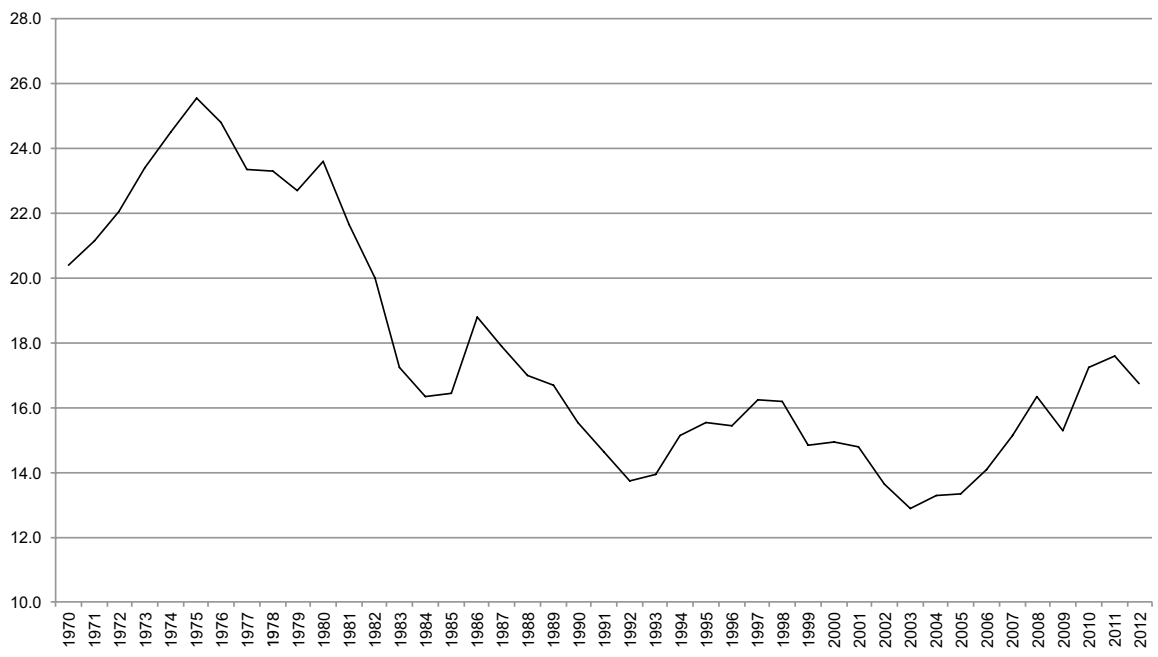

Com o objetivo de avaliar as condições necessárias para que o PIB per capita cresça a taxa de $4,7 \%$ ao ano, que o duplique a cada quinze anos, admitimos a seguinte forma funcional para o PIB per capita:

$$
y=\frac{Y}{P O P}=A\left(\frac{K}{L}\right)^{\alpha} H^{1-\alpha}\left(\frac{L}{P O P}\right)=A_{H} k^{\alpha} H^{1-\alpha}\left(\frac{L}{P I A} \times \frac{P I A}{P O P}\right)=A_{H} k^{\alpha} H^{1-\alpha} \frac{L}{P I A} B
$$

A notação é a mesma usada anteriormente: $A_{H}$ é a produtividade total dos fatores, $k$ é o estoque de capital por trabalhador, $H$ é o estoque de capital humano, $\frac{L}{P I A}$ é a razão entre o trabalho total e a PIA e $B$ o bônus demográfico.

Adicionalmente, adotamos as seguintes hipóteses: i) taxa de crescimento do capital humano de 1,2\% a.a., a mesma que ocorreu entre 2001 e 2012; ii) taxa de crescimento populacional de $0,64 \%$ a.a. nos quinze anos, de acordo com projeções do IBGE, e crescimento médio da PIA de $0,94 \%$ a.a., que corresponde a um bônus demográfico de $0,3 \%$ a.a.; iii) $\frac{L}{P I A}$ constante nos próximos anos; iv) participação do capital na renda de $40 \%$; e v) taxa de depreciação de 3,5\% a.a. O crescimento da PTFH (calculada considerando capital humano) e da taxa de investimento serão dados por diferentes cenários com as taxas de expansão da PTF variando entre $1 \%$ a.a. e um máximo de $3 \%$ a.a. enquanto as taxas de investimento variam entre $18 \%$ e $28 \%$. 
Tabela 13: Crescimento do PIB Per Capita no Brasil

\begin{tabular}{c|cccccc}
\hline & \multicolumn{7}{|c}{ Taxa de investimento } \\
\hline PTFH & $18 \%$ & $20 \%$ & $22 \%$ & $24 \%$ & $26 \%$ & $28 \%$ \\
\hline $1,0 \%$ & $3,0 \%$ & $3,3 \%$ & $3,6 \%$ & $3,9 \%$ & $4,3 \%$ & $4,6 \%$ \\
$2,0 \%$ & $4,0 \%$ & $4,3 \%$ & $4,6 \%$ & $4,9 \%$ & $5,3 \%$ & $5,6 \%$ \\
$2,5 \%$ & $4,5 \%$ & $4,8 \%$ & $5,1 \%$ & $5,4 \%$ & $5,8 \%$ & $6,1 \%$ \\
$3,0 \%$ & $5,0 \%$ & $5,3 \%$ & $5,6 \%$ & $5,9 \%$ & $6,3 \%$ & $6,6 \%$ \\
\hline
\end{tabular}

A Tabela 13 contém as projeções do PIB per capita. Com taxas de investimento de $18 \%$ o PIB per capita somente crescerá em ritmo suficiente caso a PTFH cresça a uma velocidade de $3 \%$ ao ano, muito elevado para os padrões nacionais e não observada nem durante a década de 1970. Para que o país tenha um crescimento que possibilite dobrar o PIB per capita é necessário um investimento da ordem de $24 \%$ ao ano associada a um crescimento de $2 \%$ da PTF (observado somente no milagre), um cenário bastante otimista observando-se os últimos anos da experiência brasileira.

\section{POLÍTICA ECONÔMICA: RESTRIÇÕES E RECOMENDAÇÕES}

A principal restrição macroeconômica para que a economia brasileira dobre a renda per capita em quinze anos é a baixa taxa de investimento como demonstrou as simulações da contabilidade de crescimento da seção anterior e a análise histórica dos países asiáticos e do Brasil apresentadas neste trabalho. O aumento da taxa de investimento requer aumento substancial da taxa de poupança doméstica e, portanto, redução do consumo como proporção do produto nacional.

A mecânica de uma política econômica que tenha como escopo o aumento da taxa de poupança doméstica não é difícil de ser desenhada. Todavia, ela somente será factível, do ponto de vista político, com um Pacto de Crescimento, subscrito por todos os grandes partidos políticos brasileiros.

O final da hiperinflação brasileira, com o Plano Real, não teve como pré-requisito um Pacto de Estabilização porque a população pobre, que pagava o imposto inflacionário, compreendeu que o voto era uma arma que ela poderia usar para se ver livre do imposto absurdo. Os demais grupos da sociedade foram obrigados a se entenderem e encontrarem novo equilíbrio. Não restaram aos demais partidos políticos a opção de se renderem diante da evidência empírica de que o combate à inflação produz votos que elege Presidente da República.

A economia política do aumento da taxa de poupança é completamente diferente da estabilização porque não há como aumentar a poupança sem que a União, os Estados e os Municípios o façam. Esse aumento da poupança implica redução dos gastos públicos e aumento dos impostos, ambos como proporção do PIB. O custo do aumento da poupança pública é imediato, mas os benefícios, privados e sociais, demoram um pouco. O horizonte do político é a próxima eleição. Logo, 
sem que todos concordem não há como levar a cabo uma política econômica que exija sacrifício no curto prazo.

O Pacto Político do Crescimento deveria, então, contemplar uma política de investimento público que receberia apoio da sociedade brasileira em prazo curto. O Brasil é um país que tem várias instituições excludentes. O direito de propriedade é um pilar de qualquer sociedade que deseja tornar-se rica. Todavia, a urbanização que ocorreu no Brasil levou boa parte da nossa população a viver em favelas onde o direito de propriedade não existe ou é bastante frágil. A reforma urbana tornando as favelas bairros com toda infraestrutura deve ser prioridade num programa de investimento público. Este reforma deve contemplar a construção de sistemas de transporte público que nos aproxime dos sistemas existentes no primeiro mundo.

O Pacto de Crescimento tem, portanto, que aumentar as taxas de poupança e de investimento do setor público. É impossível fazê-lo sem que haja corte no consumo do governo e aumento de impostos. A sociedade brasileira se opõe ao aumento da carga tributária alegando que os políticos são corruptos. Alega-se que o aumento dos impostos terminaria nos bolsos dos políticos. Existem piadas pitorescas que transmitem essa visão. Conta-se que foi oferecida a um ex-governador uma propina de $10 \%$ do valor da obra. Ele ficou indignado com tal oferta respondendo que não era garçom e que sua comissão era de $20 \%$.

Como fazer um Pacto de Crescimento que seja crível e que convença o eleitor de que o dinheiro não será desviado pelos políticos? O Pacto teria que ser feito por emenda constitucional que estabeleça regras para as finanças públicas por um período de vinte anos. Em primeiro lugar, ao invés de déficit público o governo produziria um superávit nominal, ciclicamente ajustado, isto é, o setor público deixaria de usar a poupança privada para financiar suas despesas e teria uma poupança positiva.

Em segundo lugar, o Artigo 167 da Constituição que proíbe a vinculação de receita de impostos a fundo seria revogado, criando-se um Fundo da Reforma Urbana que seria administrado pelo BNDES. Esse fundo teria recursos de impostos da União, dos Estados e dos Municípios, e seria, na verdade uma poupança compulsória do setor privado. A aplicação de recursos do Fundo exigiria contrapartida da União, dos Estados e dos Municípios para evitar que essas entidades diminuam os investimentos existentes atualmente, impedindo que haja substituição num comportamento típico de carona (free rider, em inglês).

Em terceiro lugar, o Pacto proibiria qualquer déficit público quase fiscal seja pelo Tesouro ou pelo Banco Central, usando-se algum tipo de artifício contábil. Nenhum banco oficial poderia emprestar recursos com taxa de juros inferior às taxas de juros dos títulos públicos de longo prazo do Tesouro Nacional, tampouco os Fundos pertencentes aos trabalhadores, como o FGTS, poderiam ser expropriados e renderem taxas de juros reais negativas.

O aumento da taxa de poupança doméstica teria como consequência impedir que ocorra a apreciação da taxa de câmbio real, um fenômeno recorrente na economia brasileira quando a taxa de crescimento aumenta. 
O fato de que a principal restrição para que um novo milagre econômico ocorra em nosso país seja a taxa de poupança não significa dizer que a educação não seja uma prioridade. A absorção de novas tecnologias é essencial para o aumento da produtividade, mas ela requer capital humano.

A literatura acerca da importância da educação nos processos de crescimento econômico sugere que países próximos à fronteira tecnológica necessitam de educação de nível superior enquanto países distantes da mesma necessitam de educação de ensino médio'. Dessa forma, o Brasil deve investir mais em educação no ensino fundamental/médio de forma a preparar a mão de obra local a adotar as tecnologias disponíveis no mundo.

O processo de massificação da educação no ensino fundamental já foi realizado e no ensino médio encontra-se em andamento. O próximo passo deve ser a melhora da qualidade ${ }^{10}$. No entanto, diferentemente do que se imagina o problema da educação pública no Brasil não é um problema de carência de recursos ${ }^{11}$, mas sim de gestão ${ }^{12}$. O diretor da escola pública deve ter instrumentos, de incentivos e de punição, para que objetivos bem definidos de qualidade da educação sejam alcançados.

\section{CONCLUSÕES}

Os países asiáticos, China, Coreia do Sul, Hong Kong, Japão, Cingapura e Taiwan, que dobraram a renda per capita em quinze anos, ou menos, tiveram como principais fontes do crescimento econômico a acumulação de capital físico e capital humano.

O Brasil quando dobrou a renda per capita na década de 1970 teve como principais fontes de crescimento o aumento da produtividade total de fatores, a acumulação de capital físico e o aumento da proporção trabalhadores/população.

A principal restrição macroeconômica para que o Brasil volte a dobrar a renda per capita num período de quinze anos é a baixa taxa de investimento. $\mathrm{O}$ aumento da taxa de investimento necessita de um aumento substancial da taxa de poupança doméstica.

Nenhum partido político isoladamente seria capaz de "vender" ao eleitor um

\footnotetext{
${ }^{9}$ Para mais detalhes ver Aghion et al. (2006) e Vandenbussche et al. (2006).

${ }^{10}$ Hanushek e Kinko (2000) enfatizam a importância da qualidade da educação para o crescimento.

${ }^{11} \mathrm{O}$ gasto brasileiro não é muito inferior ao de outros países. A distribuição dos recursos com grande peso do ensino superior é o principal problema. Mais, o efeito demográfico fará com que o montante gasto por aluno aumente nos próximos anos mesmo que o percentual do PIB gasto com educação se mantenha constante. O efeito demográfico elevará os gastos por estudante em $17 \%$ em 2023 em comparação com 2011, 34\% entre 2033 e 2011 e 67\% entre 2050 e 2011.

${ }^{12}$ Hanushek (1997) mostra que o desempenho dos alunos nos testes não possui relação direta com o montante de recursos gastos.
} 
programa que, no curto prazo, reduza o consumo do governo como proporção do PIB e aumente a carga tributária. Para viabilizar esse programa há que se fazer um Pacto de Crescimento com o apoio dos principais partidos políticos. Esse Pacto teria três objetivos: i) tornar a poupança pública positiva; ii) criar poupança forçada que seria utilizada num Fundo de Reforma Urbana, administrado pelo BNDES; e iii) proibir qualquer tipo de déficit público quase fiscal, seja pelo Tesouro Nacional ou pelo Banco Central do Brasil.

O fato de que a principal restrição macroeconômica para a duplicação do PIB per capita seja a taxa de poupança não significa dizer que a educação não deva ter prioridade. A ampliação das matrículas no ensino médio e a melhora da qualidade do ensino são fatores de suma importância. Para atingir este objetivo, a educação requer uma reengenharia na gestão com uma reforma que ofereça ao administrador instrumentos de incentivos e de punição para que se atinjam objetivos de qualidade previamente determinados. Essa reengenharia não demandaria muitos recursos adicionais.

\section{REFERÊNCIAS BIBLIOGRÁFICAS}

Acemoglu, Daron e Robinson, James (2012) Why Nations Fail: The Origins of Power, Prosperity, and Poverty, New York: Crown Business.

Aghion, Philippe, Boustan, Leah, Hoxby, Caroline e Vandenbussche, Jerome (2005). “Exploiting States' Mistakes to identify the causal impact of higher education on growth," mimeo.

Barbosa Filho, Fernando e Pessôa, Samuel (2013). "Pessoal ocupado e jornada de trabalho: uma releitura da evolução da produtividade no Brasil”, Texto para Discussão do IBRE.

Barbosa Filho, Fernando (2013). "Produto potencial brasileiro: impactos da produtividade, da demografia e da jornada de trabalho". Mimeo.

Barro, Robert and Jong-Wha Lee (2010), "A new data set of educational attainment in the world, 1950-2010”, NBER Working Paper 15902.

Bils, Mark; Klenow, Peter J. (2000). “Does schooling cause growth?” American Economic Review 90 (5): 1160-1183.

Feenstra, Robert C., Robert Inklaar e Marcel P. Timmer (2013), “The next generation of the penn world table" available for download at www.ggdc.net/pwt.

Hanushek Eric (1997). "Assessing the effects of school resources on student performance: An update". Educational Evaluation and Policy Analysis, 19, 141-164.

Hanushek, Eric e Kinko, Dennis (2000). "Schooling, labor-force quality, and the growth of nations". The America Economic Review, 90(5): 1184-1208.

Vandenbussche, Jérôme, Philippe Aghion e Costas Meghir (2006). "Growth, distance from frontier and composition of human capital,” Journal of Economic Growth, 11: 97-127. 